\title{
Phthalocyanines Structure Versus Photodynamic Effectiveness towards Pathogenic Microorganisms: Our Recent Experience
}

\author{
Vanya Mantareva ${ }^{1 *}$, Ivan Angelov ${ }^{1,3+}$, Meliha Syuleyman ${ }^{1}$, Vesselin Kussovski ${ }^{2}$, Ivelina Eneva ${ }^{1}$, \\ Latchezar Avramov ${ }^{3}$, and Ekaterina Borisova ${ }^{3}$ \\ ${ }^{1}$ Institute of Organic Chemistry with Centre of Phytochemistry, Bulgarian Academy of Sciences, \\ 9 Acad. Georgi Bonchev st., Sofia 1113, Bulgaria \\ ${ }^{2}$ The Stephan Angeloff Institute of Microbiology, Bulgarian Academy of Sciences, 26 Acad. Georgi Bonchev st., \\ Sofia 1113, Bulgaria \\ ${ }^{3}$ Institute of Electronics, Bulgarian Academy of Sciences, 72 Tzarigradsko shose blvrd., Sofia 1784, Bulgaria \\ e-mail:* mantareva@yahoo.com, + ipangelov@gmail.com
}

\begin{abstract}
The present review paper aims to summarize our recent experience in research and development of new phthalocyanine complexes and investigations of the main photophysical, photochemical and photobiological properties which are related to antimicrobial photodynamic therapy (aPDT) as alternative method for inactivation of the resistant pathogens. The effect of functionalization of $\mathrm{Zn}$ (II) phthalocyanine (ZnPc) with biologically-active natural substances such as amino acids, sugars and steroids was studied in comparison to the basic ZnPc ring molecule. The structural features of the substitution groups were chosen to facilitate the main properties responsible for PDT outcome. For example, the linkage groups of amino acids tyrosine, phenylalanine, lysine and arginine have positive charge in physiological media to the better attachment to bacterial wall and some of them have a good fluorescence for a contribution to the visualization of the infected area. Also, ZnPcs linked to sugars and steroids was expecting to possess receptor specific selectivity. The physicochemical properties of the novel functionalized ZnPcs are presented in respect to their efficiency for a number of pathogenic bacterial and fungal species. Additionally, the complexes of two heavy metal ions such as lutetium(III) (Lu(III)) and tin(IV) (Sn(IV)) were synthesized and evaluated for antimicrobial PDT. These complexes were designed with the same structural skeleton as our previous water-soluble methylpiridyloxysubstituted phthalocyanine complexes with zinc (II), silicon (IV), germanium (IV), indium (III) and gallium (III), all with relatively promising antibacterial efficiency. (C) 2021 Journal of Biomedical Photonics \& Engineering.
\end{abstract}

\footnotetext{
Keywords: Photosensitizers; Phthalocyanines; PDT; Photochemistry; Antibacterial photodynamic therapy; aPDT.

Paper \#3445 received 28 Jul 2021; revised manuscript received 10 Sep 2021; accepted for publication 12 Sep 2021; published online 25 Sep 2021. doi: 10.18287/JBPE21.07.040202.
}

\section{Introduction}

Photodynamic therapy (PDT) is well-accepted curative modality with fast outcome after treatment, which is applicable on different acute disorders including infections $[1,2]$. The method is based on a local irradiation of the target spot of the problematic area associated with pathogens where the photosensitizer (PS) is preferably accumulated. The efficacy of PDT action depends on the saturation with molecular oxygen but usually the 
atmosphere surrounding is adequate for the process. The procedure starts with a light absorption within visible or near infrared spectra, which initiates a physical conversion of generation of first singlet excited state $\mathrm{PS}^{1}$. The absorbed energy of $\mathrm{PS}^{1}$ may relax by radiative and nonradiative conversions with high input of the intersystem crossing transition which leads to production of the triplet excited state $\mathrm{PS}^{3}$ [3]. The molecules in their triplet excited state can take part in the photochemical reactions with participation of the molecular oxygen placed in the vicinity of $\mathrm{PS}^{3}$ as well as with the surrounded bioorganic molecules as part of the structure of pathogens. The progress of the photosensitization includes different reactive oxygen species (ROS) such as singlet oxygen $\left({ }^{1} \mathrm{O}_{2}\right)$, superoxide anion $\left(\mathrm{O}^{2 \cdot-}\right)$, hydroxyl radical $(\cdot \mathrm{OH})$ and hydrogen peroxide, all causing the irreversible oxidative damage of membranes so that the development of drug resistance is not yet observed for photodynamic inactivation [4].

It is believed that the fast development of drug- and multi-drug resistance is associated with the over-use and often abuse to the presently available chemotherapeutic drugs [5]. The knowledge about the efficacy of compounds absorbing in the far-red spectral region on the local infections has more than hundred years' historical timeline. Though, the "Golden era" of discovery and common usage of antibiotics has limited the progress of development of PDT method towards pathogenic microorganisms. Since the time when the resistance problem was announced as a high social health problem, the PDT topic together with many other approaches are under consideration as alternative methods to the antibiotics treatment [6].

The structure of a PS has to be capable to accumulate in high amounts into pathogens to result in the pathogens inactivation after light irradiation with a specific wavelength [7, 8]. The research and development of new generation PS, which are especially designed for pathogenic microbes, have been under intensive research consideration $[9,10]$. The interaction of a PS with the pathogenic microbial species depends on their morphological characteristics, which have the welldefined difference for both bacterial species. For example, the bacterial wall of Gram (-) bacteria is more complicated having an additional layer than that in Gram $(+)$ bacteria, which can act as a permeability barrier to limit the drug penetration and the further inactivation. The most involved mechanisms of drug uptake are known to happen by the physical uptake of PS molecules to the membranes due to hydrophobic and charge interactions [11]. These mechanisms can act together with the membrane's receptors-interactions, which are likely delivered the sufficient amount of PS to the target cells. The studies also present the selectivity of the uptakes in randomly arranged pathogens over the surrounding organized mammalian cells [12-14]. The specific structural characteristics of the particular pathogenic specie of one group of pathogens with common features need to be considered in strength designed PS's. The focus in investigations is made on the biologically-active functional groups for substitution of PS with a goal for improvement of the chemical, physicochemical and photoinactivation PS properties [15].

For these reasons, the new generation photosensitive drugs used for antimicrobial PDT (aPDT) or photodynamic inactivation (PDI), as well as the photodisinfection of medical devices related to human activity and treatment, have a well-defined chemical structure, cationic charge and hydrophilic or amphiphilic nature [16]. Nowadays only few numbers of metal coordinated phthalocyanine complexes (MPcs) of zinc $(\mathrm{ZnPc})$, aluminum $\left(\mathrm{AlPcS}_{\mathrm{n}}\right)$ and silicon $(\mathrm{Pc} 4)$ are clinically approved for PDT of different tumor localization [17]. However, the knowledge about these drugs suggested the low uptake capacity and non-selective efficiency on pathogenic bacteria and fungi [18]. On the other hand, taking into account the structural flexibility and the advanced optical properties of MPcs, such as the long wavelength of absorption (>680 nm), the high molar absorptivity $\left(>10^{5} \mathrm{M}^{-1} \cdot \mathrm{cm}^{-1}\right)$, lack of dark toxicity and relatively high photocytotoxicity, the promising MPcs with advanced properties towards pathogenic species are under development $[19,20]$.

The review presents new research studies, together with already published results, in order to give a general picture of the effects that functionalizing biocompatible groups have on the overall properties of MPcs photosensitizers when used against pathogens.

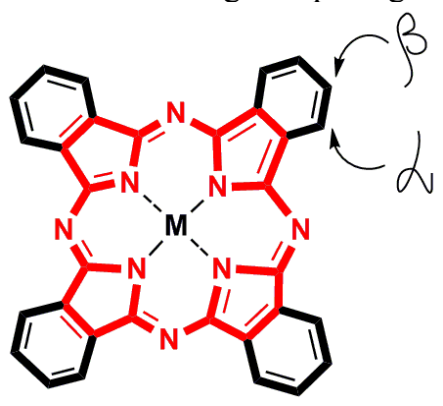

Fig. 1 Chemical structure of phthalocyanine complex (MPc) with the positions for conjugation.

\section{Biologically-active groups to $\mathrm{Zn}$ (II)- phthalocyanines towards pathogens}

The phthalocyanine molecule possess structural characteristics of symmetrical planar skeleton with sixteen positions for substitutions on the ring macrocycle and one or two axial positions for substitutions to the coordinated metal ions (M) (Fig. 1).

The peripherally substituted MPcs are assumed as more likely to interact with the target cells because of the extent area of these groups as well as the axial substitutions with bulky groups, which influence on the aggregation behaviour and arrangement of photo-inactive molecular associates [21].

\subsection{Amino acids substituted Zn(II)-phthalocyanines}

The chemical conjugates of phthalocyanines (Pc) with amino acids have been of research interest during more 
than two decades [22-24]. The intention in the beginning was the improvement of solubility of highly hydrophobic Pc molecule. The further studies aim modifications of properties of absorption, fluorescence and singlet oxygen generation $[25,26]$. In addition, some new essential biological properties appear related to the cell-specificity, the uptake and the photocytotoxicity. In our studies, four amino acids tyrosine, phenylalanine, lysine and arginine were selected to advance the properties of $\mathrm{ZnPcs}$ as photosensitizers [27]. The non-essential amino acids phenylalanine, lysine and arginine (for adolescent) are well documented with their positive physiological effects, curative action and the wide usage in medicine as prodrugs [28]. Next to their biological functions, they also have some specific properties as, for example, is the detectable fluorescence of tyrosine and phenylalanine [29]. Other selected amino acids are lysine and arginine, which are well documented with their ability of excellent penetration and interaction with cell membranes [30,31]. These properties were expected to affect the physicochemical properties and the easy localization of ZnPc's functionalized with amino acids in sufficient amount for an effective pathogen's photoinactivation. Ultimately the conjugation of two biologically-active molecules was expected to lead to a photosensitive compound with synergistic action on the target. Presently, treatments of acute infections related to pathogenic species have been settled with the chemotherapy with conventional and newly developed antibiotics [32]. Even so they are known to induce several side effects due to non-selectivity of uptakes, which can lead to harmful toxicity in healthy host tissues and the fast development of drug resistance to the treatment regime [33].

\subsubsection{Synthesis of ZnPcs linked to amino acids}

New bioconjugates of $\mathrm{Zn}$ (II) phthalocyanine with four and eight amino acids were synthesized. Two molecules of different origin were connected by amide bond between carboxyl groups of tyrosine, phenylalanine, lysine and arginine, and amino (aminophenoxy) group of phthalocyanine placed on four and eight peripheral positions to the Pc ring in the presence of coupling agents (Fig. 2).

The conjugation was performed using multi-step procedure to prepare two starting tetra- and octaaminophenoxy- substituted $\mathrm{Zn}(\mathrm{II})$ phthalocyanines. Briefly, the used synthetic pathway presented in Fig. 3 starts with synthesis of dinitriles with nitrophenoxy group by following the reaction step of cyclotetramerization in the presence of zinc salt, the next step by reaction of reduction of nitro groups to amino groups were carried out according to the literature [34-36].
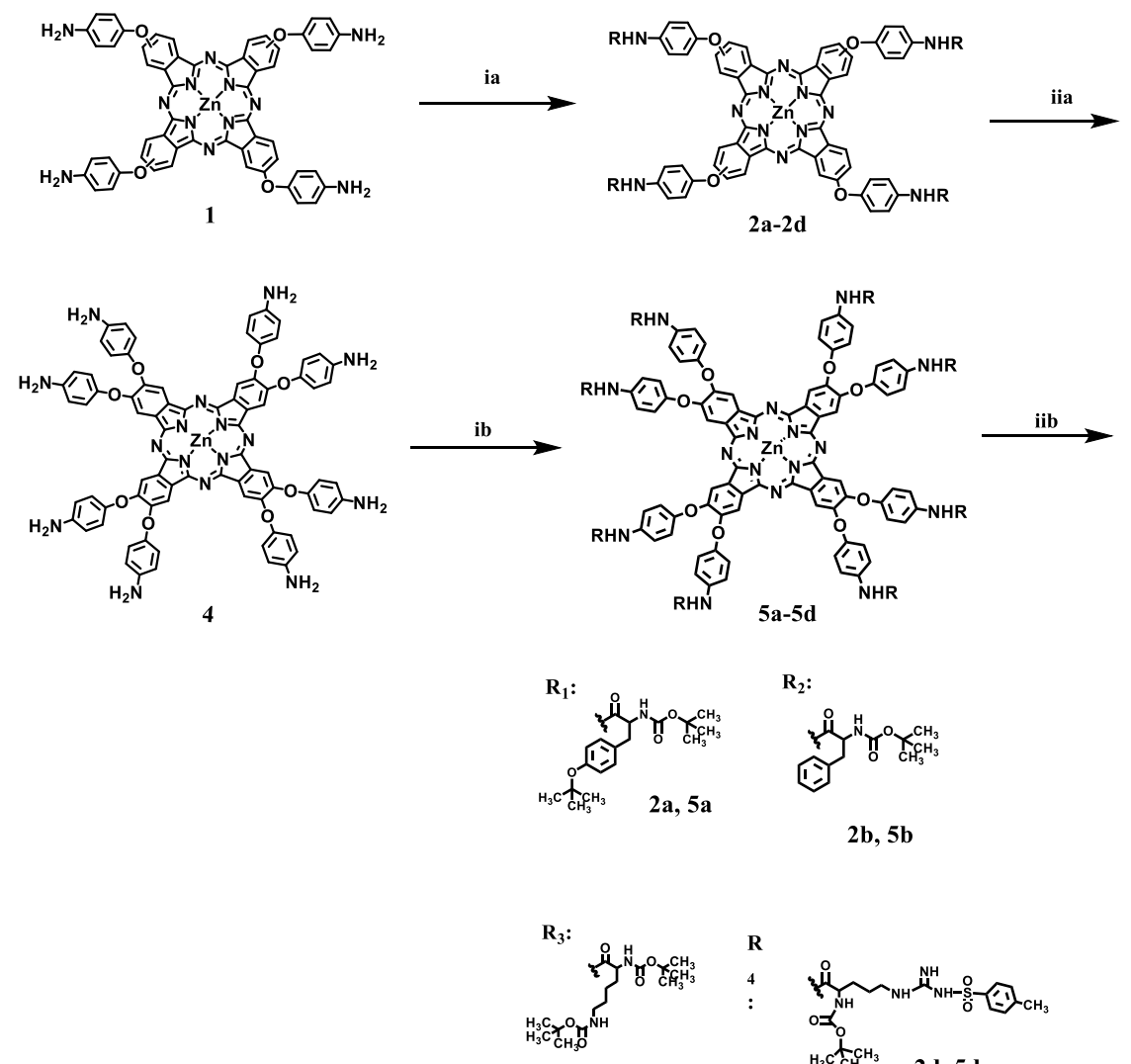

$2 c, 5 c$
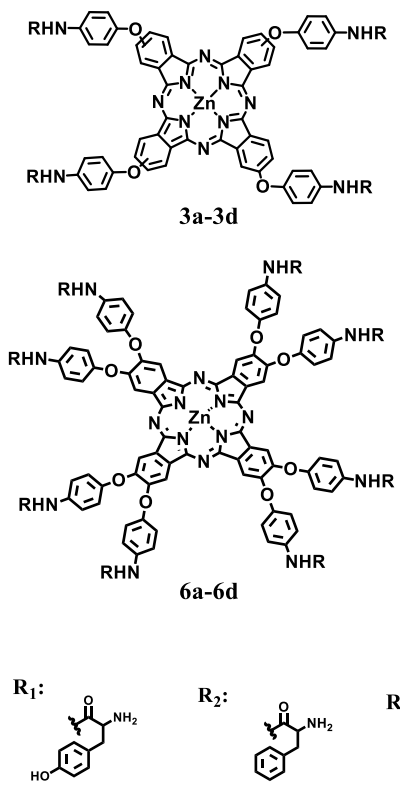

$\mathrm{R}_{2}$ :

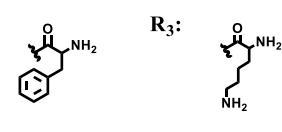

$2 b, 5 b$

$3 a, 6 \mathbf{a}$

$3 \mathbf{b}, \mathbf{6 b}$

$3 c$

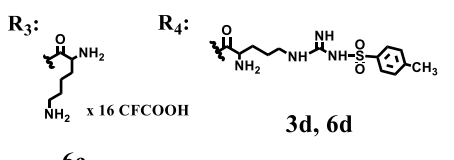

$6 \mathrm{c}$

Fig. 2 Synthesis of $\mathrm{Zn}$ (II) phthalocyanines linked to amino acids (tyrosine, phenylalanine, arginine and lysine). Reactions and conditions: (ia) protected amino acid-OH, DMTMM, NMM, THF, ice bath, rt; (ib) protected amino acid-OH, DMTMM, NMM, DMF, ice bath, rt; (iia) TFA, THF, rt; (iib) TFA, DMF, rt. 


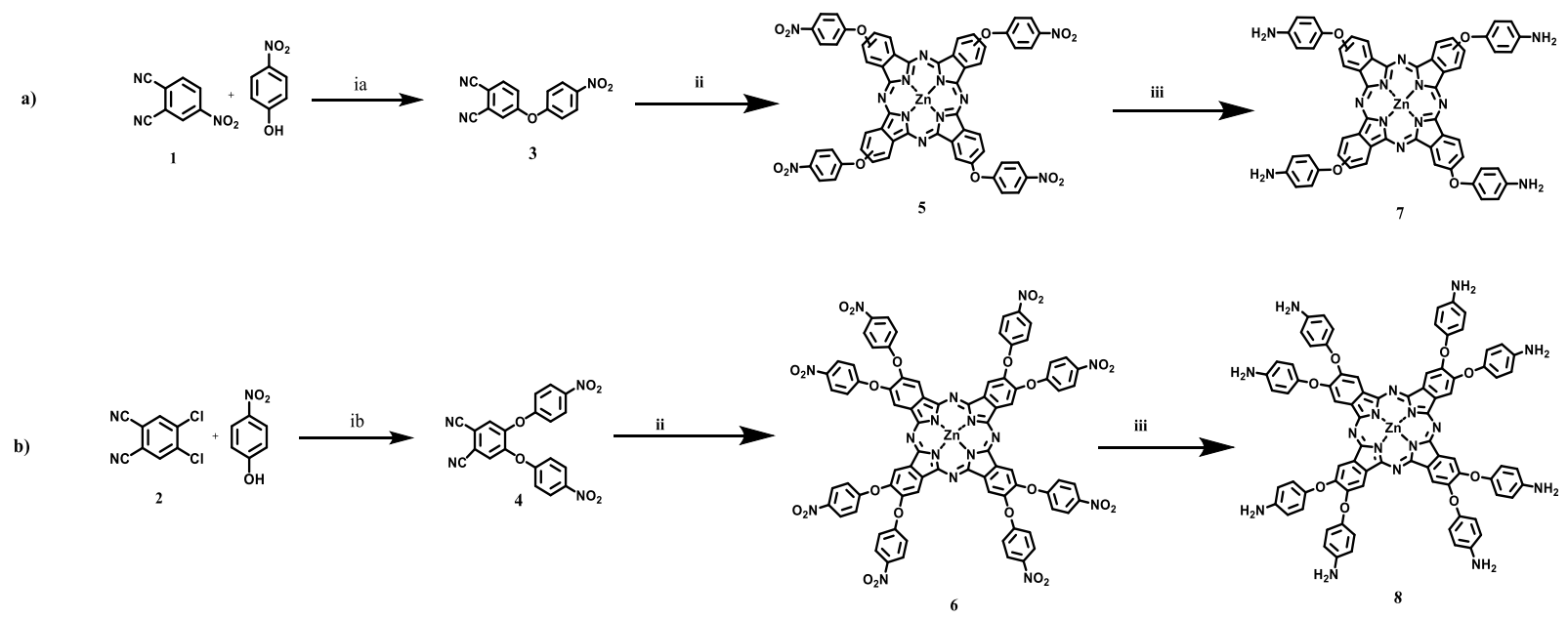

Fig. 3 Synthesis $\mathrm{Zn}(\mathrm{II})$ phthalocyanines for conjugation: (ia) K2CO3, dry DMF, RT, Ar; (ib) K2CO3, dry DMF, $90{ }^{\circ} \mathrm{C}$, Ar; (ii) $\mathrm{Zn}(\mathrm{OAc})_{2}$, DBU, 1-pentanol; (iii) dry DMF, $\mathrm{Na}_{2} \mathrm{Sx}_{2} \mathrm{H}_{2} \mathrm{O}$.

$\mathrm{Zn}(\mathrm{II})$ conjugates with the selected amino acids were obtained with a relative yield: $44 \%$ for lysine conjugates to $87 \%$ for phenylalanine and tyrosine derivatives. The conjugates $\mathrm{ZnPc}$ with selected amino acids were analysed, with such known spectroscopic techniques as IR, ${ }^{1} \mathrm{HNMR}$, MS and UV-Vis spectroscopy. They showed excellent solubility in most organic solvents. The aimed high solubility was observed for two $\mathrm{ZnPc}$ conjugates with lysine and arginine (Fig. 2-6a and 6c) showing water solubility.

\subsubsection{Physicochemical properties}

Electronic absorption spectra of the conjugates with amino acids and basic photophysicochemical properties were measured in Dimethyl Sulfoxide (DMSO) and data are collected in Table 1. The absorption spectra were all similar, which is characteristic for non-aggregated metalphthalocyanines. They showed a B band at 352 to $366 \mathrm{~nm}$, a band at $617 \mathrm{~nm}$ and intensive sharp Q-band at 680 to $683 \mathrm{~nm}$, which strictly followed the Lambert-Beer law. The amino acids lead to red shifts of the absorption maxima with 10 to $12 \mathrm{~nm}$ compared to unsubstituted $\mathrm{ZnPc}$ but the type of the amino acids less influence the position of the absorption maxima of the compounds. Upon excitation at $360 \mathrm{~nm}, 610 \mathrm{~nm}$ and $660 \mathrm{~nm}$ they showed relatively high fluorescence emissions at 690 to $694 \mathrm{~nm}$ but with low fluorescence quantum yield $\left(\Phi_{\mathrm{F}}\right)$ from $0.018-0.069$ except for tetra tyrosine substituted $\mathrm{Zn}$ (II) phthalocyanine $\left(\Phi_{\mathrm{F}}=0.12\right)$. The lower values of the fluorescence quantum yield of the phthalocyanines may be due to the physical quenching by the bulky substituents on the amino acids in addition to the influence of free amino groups on peripheral positions of the $\mathrm{ZnPc}$ ring. The high values of the fluorescence quantum yield of the tetra tyrosine substituted $\mathrm{ZnPc}$, which is comparable with the fluorescence quantum yield of unsubstituted $\mathrm{ZnPc}$, is may be due to the contribution in the total fluorescence of the phthalocyanine and tyrosine molecules. Recently Zhang et al. [37] showed that the introduction of $\mathrm{NH}_{2}$ - groups to $\mathrm{ZnPc}$ may have different effects than the other studied substituents $\left(-\mathrm{OCH}\left(\mathrm{CH}_{3}\right)_{2}, \mathrm{H}, \mathrm{NO}_{2}\right)$. This group can incite numerous roles: a good electron donor, a strong proton acceptor, a hydrogen bonding formation ability and a good ligand for coordination of metal ions. Moreover, the amino-substituted $\mathrm{ZnPc}$ may show very low fluorescence quantum yield as the new $\mathrm{Zn}$ (II) phthalocyanines with tyrosine, arginine, lysine and phenylalanine except tetra tyrosine substituted $\mathrm{Zn}(\mathrm{II})$ phthalocyanine on symmetrical peripheral positions presented but the fluorescence lifetime does not decrease significantly.

The lifetime of the bio-conjugates is comparable with lifetime of the unsubstituted ZnPc. The lower values of the fluorescence quantum yield and not so significant lowering of the lifetimes of new compounds compared to unsubstituted $\mathrm{ZnPc}$ can be explained by the effect of quenching of the unprotected $\mathrm{NH}_{2}$-groups, which is in contribution to a high electron density of the molecules. Therefore, it is more likely to occur the photo-induced electron transfer (PET) and as a consequence is decrease of fluorescence yields. The protection with tetrabutoxycarbonyl group (Boc), which is electron withdrawing group can reduce the electron density of nitrogen atom and this leads to less effective quenching of the singlet excited state of the conjugates through PET [37]. This observation supports the reductive quenching of amino groups, which disfavour the intersystem crossing based on the intramolecular PET effect.

The efficiency of the $\mathrm{Zn}(\mathrm{II})$ conjugates with amino acids in generating singlet oxygen, as reflected by the rate of decay of the singlet oxygen quencher 1,3 - diphenylisobenzofuran (DPBF) in DMSO, was also examined. Tetra conjugates showed higher values according to their octa analogues as tetra tyrosine and phenyalanine conjugates $\left(\Phi_{\Delta}=0.63\right.$ and 0.71$)$, with exception of tetra lysine conjugates, which has lower value of singlet oxygen $\left(\Phi_{\Delta}=0.36\right)$ than its octa analogue $\left(\Phi_{\Delta}=0.57\right)$ and almost same values with arginine compounds - $\left(\Phi_{\Delta}=0.39\right)$ for tetra compound and $\left(\Phi_{\Delta}=0.40\right)$ for octa- substituted $\mathrm{ZnPc}$ derivatives. 
Table 1 Physicochemical properties of Zn(II) phthalocyanines linked to amino acids in DMSO.

\begin{tabular}{ccccccc} 
PS & $\lambda_{\text {abs }}(\mathbf{n m}),(\log \varepsilon)$ & Emission $\lambda_{\text {em }}(\mathbf{n m})$ & $\boldsymbol{\Phi}_{\mathbf{F}}$ & $\boldsymbol{\tau}_{F}(\mathbf{n s})$ & $\boldsymbol{\Phi}_{\Delta}$ & $\mathbf{d C} / \mathbf{d t}(\mathbf{M} / \mathbf{s})$ \\
\hline 3a & $680(3.02), 352(-)$ & 692 & 0.12 & 2.91 & 0.63 & $3.1 \times 10^{-10}$ \\
\hline 6a & $680(4.36), 364(3.94)$ & 689 & 0.04 & 2.03 & 0.38 & $32 \times 10^{-10}$ \\
\hline 3b & $682(4.23), 353(3.93)$ & 693 & 0.069 & 2.82 & 0.71 & $5.63 \times 10^{-10}$ \\
\hline 6b & $683(4.17), 357(3.88)$ & 690 & 0.018 & 2.67 & 0.23 & $3.5 \times 10^{-10}$ \\
\hline 3c & $683(3.63), 356(3.38)$ & 693 & 0.047 & 2.85 & 0.36 & $13.5 \times 10^{-10}$ \\
\hline 6c & $681(5.28), 360(4.86)$ & 690 & 0.03 & - & 0.57 & $2.20 \times 10^{-10}$ \\
\hline 3d & $682(4.27), 352(3.97)$ & 694 & 0.055 & 2.89 & 0.39 & $1.53 \times 10^{-10}$ \\
\hline 6d & $682(4.02), 355(3.73)$ & 690 & 0.038 & 2.56 & 0.40 & $7.89 \times 10^{-10}$ \\
\hline ZnPc* & $672(5.21), 341(2.61)$ & 679 & 0.20 & 3.99 & 0.67 & $0.94 \times 10^{-10}$
\end{tabular}

The formation of molecular singlet oxygen does not affect the intensity of the Q-band of the conjugates, which suggests that there is no photooxidative effect on the phthalocyanine molecules during their irradiation. The option of singlet oxygen physical quenching is more probable by the eight peripheral substituents than four groups on $\mathrm{ZnPc}$ ring molecule. The physical quenching by bulky substituents was known to diminish the singlet oxygen quantum yields of some other substituted phthalocyanines [38]. The low values of the conjugates $(0.23-0.40)$ correlate to the quenching of excited state due to PET effect of the amino groups closed to $\mathrm{ZnPc}$ (phenylamine and benzylamine groups) resulting in the lower singlet oxygen generation. This effect can be inhibited by the distance of $\mathrm{NH}_{2}$ to the Pc-molecule, acidity of media and protonation of amino groups [39].

The photostability study of the tetra and octa Zn(II) phthalocyanines with the amino acids tyrosine, phenylalanine, lysine and arginine was carried out by following the absorption spectra during irradiation $\left(60 \mathrm{~mW} \cdot \mathrm{cm}^{-2}\right.$ at $665 \mathrm{~nm}$ wavelength). All studied compounds were as effective as unsubstituted $\mathrm{ZnPc}$ which showed relatively high stability at the applied light. The results are summarized in Table 1 showing the rates $(\mathrm{dC} / \mathrm{dt})$ in one of the same order of magnitude. The obtained rates suggested an optimal photostability without formation of the by-products due to irradiation. The collapse of the absorption spectra without any distortion of the shape which suggested the lack of structural alteration of phthalocyanine molecules in the spectra of irradiation was observed for all studied phthalocyanines.

\subsubsection{Uptake and photoinactivation efficacy}

Uptake of the Zn(II) conjugates with phenylalanine, lysine and arginine (Fig. 2-3b-3d and 6b-6d) on fungal cells
C. albicans were studied by using chemical extraction method which included incubation of the studied conjugates in the cellular suspensions with different cell density $\left(10^{5}-10^{8}\right.$ Colony-forming units $\left./ \mathrm{mL}(\mathrm{CFU} / \mathrm{mL})\right)$. The collected supernatants with the extraction mixtures were measured the fluorescence between $650-800 \mathrm{~nm}$ with $\lambda_{\mathrm{ex}}=637 \mathrm{~nm}$. The results obtained are presented as number of molecules (No), uptake in a one bacterial cell (No / cell). Fig. 4 shows that Zn(II)Pc linked to amino acids have relatively high uptakes with values two order of magnitute higher for $3 \mathrm{c}$ and $3 \mathrm{~d}\left(10^{11}\right)$ than for $3 \mathrm{~b}\left(10^{9}\right)$. This low uptake of $3 \mathrm{~b}$ is probably due to its low solubility at the extraction mixture (THF / SDS). The octa- compounds showed similar values $\left(10^{11}\right.$ No / cell). The compound $6 \mathrm{~b}$ showed the highest level of uptake among the octa- compounds. The typical inverse behaviour of decreasing of the accumulation of the studied conjugates with increasing of the cell density $\left(10^{5}-10^{8} \mathrm{CFU} / \mathrm{mL}\right)$ of suspensions was observed as in for the other pathogens. The obtained results are in agreement with the observation that the cellular accumulation depends on the cell density of suspension [40].

It is well studied that the cell membrane can bind more effectively the cationic compounds [41]. According to the obtained results with $\mathrm{ZnPcs}$ with phenylalanine, lysine and arginine the relatively high level of binding is a result of the amino groups which facilitate the binding to cell membrane of $C$. albicans. The interactions can occur by the hydrophobic nature of $\mathrm{ZnPc}$ or some physical force. On the other side lysine and arginine are able at physiological $\mathrm{pH}$ to act as cationic $\mathrm{ZnPcs}$ with higher accumulation and retention time of these compounds in membranes.

The photoinactivation study with Zn(II)Pcs with amino acids showed the lack of dark toxicity and low 
photocytotoxicity ( 2log) for Candida albicans (Fig. 5). The study was carried out at concentration of $10 \mu \mathrm{M}$ and irradiation on $665 \mathrm{~nm}$ wavelength by Light emitted diode (LED) (light dose $50 \mathrm{~J} \cdot \mathrm{cm}^{-2}$ at $60 \mathrm{~mW} \cdot \mathrm{cm}^{-2}$ light intensity). Only both arginine substituted compounds (3b, 3d and 6d) showed complete photoinactivation, followed from lysine substituted 3c. These results are supported by the properties of singlet oxygen generation and the uptakes.

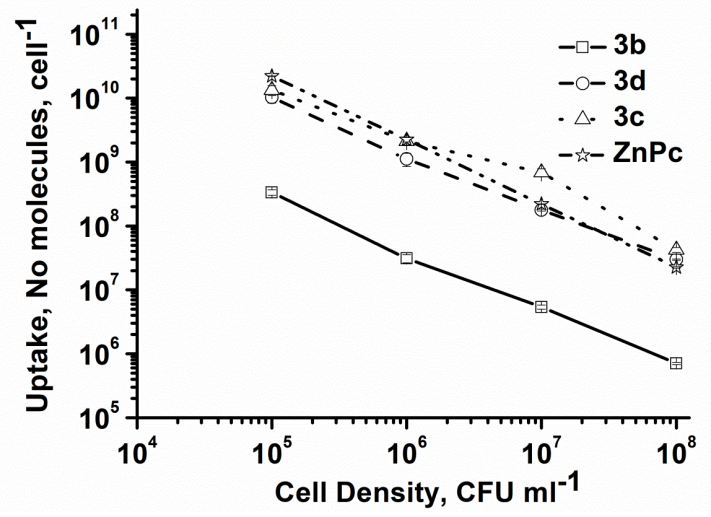

(a)

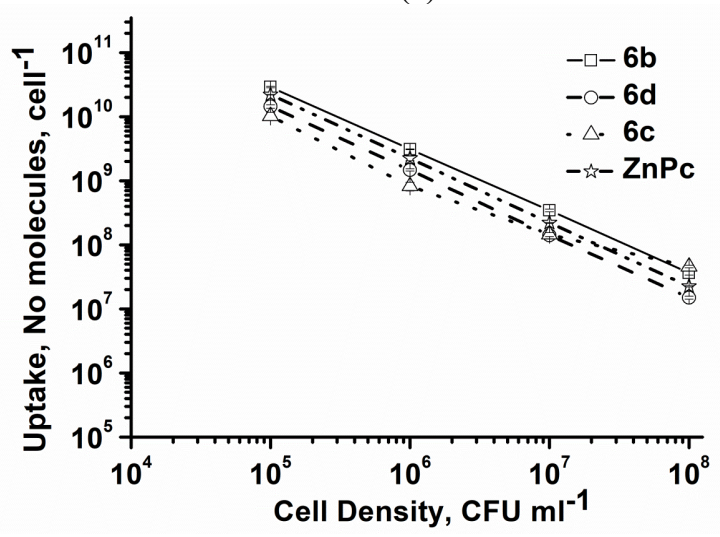

(b)

Fig. 4 Uptake of a) 3b, 3c, 3d; b) 6b, 6c, 6d (5.5 $\mu \mathrm{M})$ in dependence on the cell density of Candida albicans in suspension with incubation time $20 \mathrm{~min}$. The data are presented as means $\pm \mathrm{SD}(\mathrm{n}=3)$.

The carbohydrates such as galactosa and furanosa chemically linked to $\mathrm{ZnPc}$ were studied with low efficiency towards pathogenic microorganisms [42]. The low efficiency was also obtained with $\mathrm{ZnPc}$ conjugated with steroid [43].

\subsubsection{In vitro photocytotoxicity}

Photocytotoxicity assays were carried out with new conjugates (Fig.2-3a, 6a and 3c) in comparison with unsubstituted $\mathrm{ZnPc}$ and tetra aminophenoxy $\mathrm{Zn}$ (II) phthalocyanine $\left(\mathrm{TZnPcNH}_{2}\right)$ on two human breast cancer cells lines (MDA-MB-321 and MCF-7) and normal human cell line (MCF-10A). All of the studied conjugates (3a, 6a and $3 \mathrm{c}$ ) showed no dark toxicity in a wide concentration range $(0.15-20 \mu \mathrm{M})$ at irradiation with LED $665 \mathrm{~nm}$ and light parameters used in PDT study $\left(50 \mathrm{~J} \cdot \mathrm{cm}^{-2}\right.$ and $60 \mathrm{~mW} \cdot \mathrm{cm}^{-2}$ ) [44]. Both tyrosine conjugates (tetra- and octa-) showed similar photocytotoxicity for concentrations up to $10 \mu \mathrm{M}$ and with moderate photocytotoxicity at concentrations over $10 \mu \mathrm{M}(37 \%$ viability for $\mathrm{MCF}-7$ and $50 \%$ for MDA-MB-231). The healthy cell line (MCF-10A) were not affected by irradiation for concentration between $1-10 \mu \mathrm{M}$ from both tyrosine conjugates. Only unsubstituted $\mathrm{ZnPc}$ showed strong photocytotoxic effect towards tested cell lines. The amino acids - conjugates ( $3 \mathrm{a}$ and $6 \mathrm{a}$ ) and $\mathrm{ZnPc}$ showed negligible photocytotoxic effect on normal cells ( $\sim 80 \%$ viable cells) at concentrations bellow $10 \mu \mathrm{M}$ and significant photocytotoxicity for concentrations over $10 \mu \mathrm{M}$ for tumour cell lines (MDA-MB-231 and MCF-7). The interesting result is that the both aminophenoxy $\mathrm{Zn}$ (II) phthalocyanines used for conjugation showed very low phototoxic potential towards MDA-MB-231 tumour cells even at high dye concentrations and a lack of photocytotoxicity towards the cell lines MCF-7 and MCF- 10A.

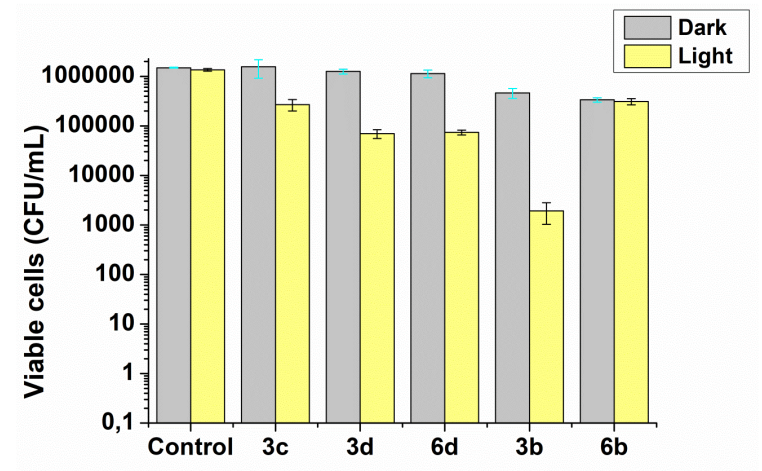

Fig. 5 Photocytotoxicity of $3 b, 6 b, 3 c, 3 d, 6 d$ on Candida albicans.

\section{$3 \mathrm{Zn}$ (II) phthalocyanines bearing both charges towards pathogens}

The present knowledge about the influence of charge on the properties related to PDT efficacy is that the cationic photosensitizers including phthalocyanine complexes (MPcs) are better than anionic and neutral MPcs [45]. An interesting group of charged compounds which appears promising as photoantimicrobials are zwitterionic photosensitizers. They have the advantage of water solubility and low aggregation capability. Typical examples of zwitterions are amino acids with one amine and one carboxylic group where the basic $\mathrm{NH}_{2}$ - group is strong enough to deprotonate acidic- $\mathrm{COOH}$ group in solution [46]. These substituents have characteristic of a dipolar ion with positive and negative parts so that the net charge of the molecule is zero.

The zwitterionic $\mathrm{Zn}(\mathrm{II})$ phthalocyanines were synthesized by the treatment with 1,3-propanesultone at nitrogen of pyridiloxy group by following the well-known procedure [47]. Briefly, the reaction starts from dinitriles prepared from commercially available 4- and 3- nitrophthalonitrile in reaction with 3-hydroxypyridine in DMSO using potassium carbonate as a base. The both 
<smiles>N#Cc1ccc(Cc2ccccn2)cc1C#N</smiles>
$\underset{\mathrm{DBU}, 120^{\circ} \mathrm{C}, \mathrm{Ar}}{\mathrm{Zn}(\mathrm{OAC})_{2}}$ A: $\mathrm{O}$ or $\mathrm{S}$

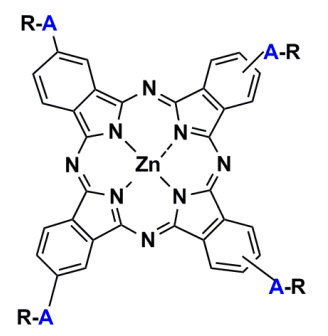

$\operatorname{ZnPc} 1, A=0$ $\mathrm{ZnPc} 2, \mathrm{~A}=\mathrm{S}$

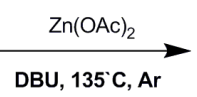

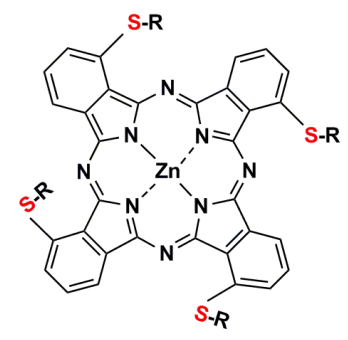

$\mathrm{ZnPc} 3$
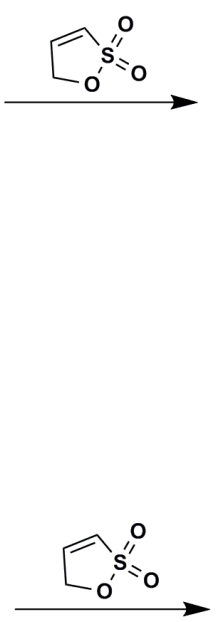

DBU, $135 \mathrm{C}, \mathrm{Ar}$

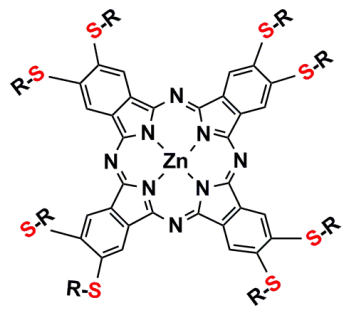

ZnPc 4

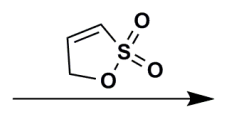

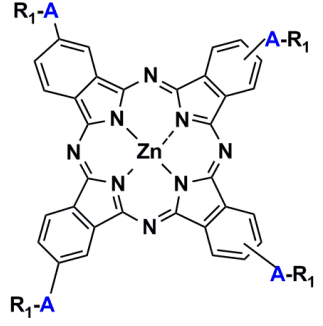

$\operatorname{ZnPc} 1.1, A=0$ $\mathrm{ZnPc} 2.1, \mathrm{~A}=\mathrm{S}$<smiles>N#Cc1cc(Sc2ccccn2)c(Sc2ccccn2)cc1C#N</smiles>

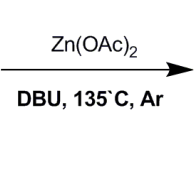

R:<smiles></smiles>

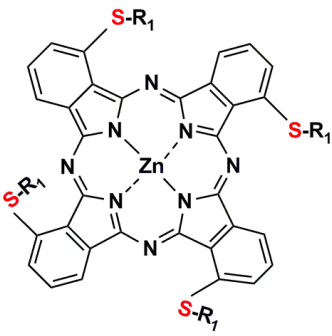

$\mathrm{ZnPc} 3.1$

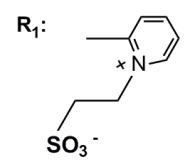

Fig. 6 Synthesis tetra-(3-/ 4-) pyridiloxy and pyridilsulfur $\mathrm{Zn}(\mathrm{II})$ phthalocyanines (ZnPc 1-4). Conditions: Zn(OAc)2, DBU, 1-pentanol and the derivatives ZnPc 1.1 - 4.1 after propanesulton in dry DMF.

reactions are productive for the chosen conditions ( $48 \mathrm{~h}$, room temperature (RT)) and give the high purity products with approximately $80 \%$ yields. The physicochemical studies of differing in the positions zwitterionic ZnPcs suggested that they have promising photoproperties for biomedicine [48]. Nowadays together with different zwitterionic compounds such as carboxybetaine, phosphocholine, sulfobetaine also many phthalocyanines bearing selected as useful substituents have been synthesized and studied for PDT efficacy [37].

Our studies with the structurally different $\mathrm{ZnPcs}$ namely as the numbers of substituents (four and eight), the bridging atoms (sulfur or oxygen) and the positions of the substitution groups (Fig. 6). The peripherally substituted $\mathrm{ZnPcs}$ are as followed: tetra- 2-(Npropanesulfonic acid) oxypyridine (ZnPc1.1); tetra- 2(N-propanesulfonic acid) mercaptopyridine (ZnPc2.1) and non-peripherally substituted compound is tetra- 2-(Npropanesulfonic acid) mercaptopyridine (ZnPc3.1), and octa- 2-(N-propanesulfonic acid) mercaptopyridine (ZnPc4.1). The bridging atom of sulfur add to absorption a red shift of approximately $10 \mathrm{~nm}(684 \mathrm{~nm})$ as compared to the oxygen bridging atom in $\mathrm{ZnPc1} 1.1(674 \mathrm{~nm})$.

Two model pathogenic bacterial strains were tested, the both associated with the acute infections to humans namely a Gram (+) pathogenic bacterium Enterococcus faecalis (E. faecalis) and the Gram (-) bacterium Pseudomonas aeruginosa ( $P$. aeruginosa), which is 
known as a hardest to the inactivate, due to bacterial wall consisting of one additional layer of phosphatidylethanolamines [49]. However, the Gram (-) species are also known with low susceptibility to the conventional therapy and with fast development of resistance to the treatment [50].

\subsection{Uptake and localization study}

The studied zwitterionic ZnPcs showed relatively high uptakes on resistant pathogenic bacterial strains of Gram (+) E. faecalis and Gram (-) P. aeruginosa as suspensions with different cell densities and as early stage biofilms formation [51]. It is assumed that the uptakes occur by a non-chemical attachment to the bacterial species in suspension or organized as biofilms. These compounds showed a high tendency of aggregation in water and buffered solution which can lead to ineffective photodynamic process. A Gram (-) P. aeruginosa was observed with less amount of the tested $\mathrm{ZnPc1} 1.1-4.1$ with approximately one order of magnitude that the Gram $(+)$ specie. The typical inversely proportional behaviour for the uptake values at the increasing cell densities was observed. This phenomenon is typical for any suspensions and repeated independently on the applied PS and type of treated bacteria since the first report for the Gram-negative Escherichia coli [52]. Many different pathogens and photosensitizing compounds were studied with similar accumulation behaviour $[53,54]$. This may occur due to higher competition between the $\mathrm{ZnPc}$ molecules to bind to one bacterial cell with increasement of the bacterial density and as a consequence with the fewer available binding sites. The knowledge that the binding ability of the incubated $\mathrm{ZnPcs}$ can occur by hydrophobic or electrostatic interactions, or hydrogen bounding is valid also for zwitterionic ZnPcs, which possess the both charges in one substitution group. Obviously, this characteristic tends to improve the uptakes showing the almost equal values for octa-substituted ZnPc 4.1 for the both bacterial species.

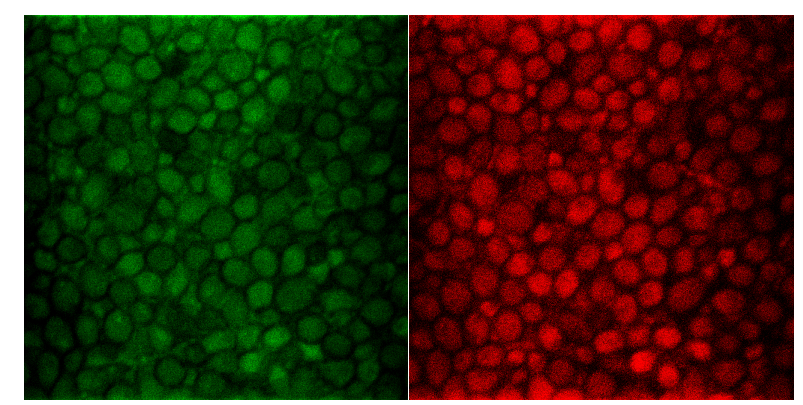

Fig. 7 The typical fluorescence confocal images of the slice of C. albicans biofilm (excitation $488 \mathrm{~nm}$; emission 530-580 $\mathrm{nm}$ for the native fluorescence and excitation $635 \mathrm{~nm}$; emission 660-720 nm for ZnPc1.1).

The biofilm's penetration and localization of zwitterionic ZnPcs in the fungal biofilms were evaluated by means of confocal laser scanning fluorescence microscopy (Fig. 7). The study is based on the fluorescence difference between the natural chromophores of cells which can be visualized by excitation with lasers $365 \mathrm{~nm}$ and $488 \mathrm{~nm}$ to image the typical green fluorescence in the region of emission $520-580 \mathrm{~nm}$. The red fluorescence of $\mathrm{ZnPc1.1-4.1}$ was observed at excitation with laser $635 \mathrm{~nm}$ for the emission spectra 660-740 nm as previously observed for bacterial biofilms $[55,56]$. By the overlapping of the green channel and red channel of fluorescence signals was observed the significant $\mathrm{ZnPc1} 1$ spreading throughout the biofilms. This was shown by two modes of observation, namely the fluorescence and transmittance. Among the studied ZnPcs, only non-peripheral $\mathrm{ZnPc3} .1$ was observed with limited penetration in biofilms. The observed sufficient accumulation of $\mathrm{ZnPc1.1}, 2.1$ and 4.1 into pathogenic bacterial biofilms suggested their potential for sufficient photodynamic inactivation. The different structures of the photoactive compounds influence the membrane permeability and on the uptakes [57].

\subsection{Photoinactivation and dark cytotoxicity study}

The cells were evaluated with saturation enough to expect the high generation of ROS products, which affect easily the membranes in the close vicinity of $\mathrm{ZnPc} 4.1$ with eight substitution groups was studied to have higher inactivation of planktonic and biofilm cultured. The photodynamic inactivation studies with zwitterionic ZnPc1.1-4.1 suggested different effectiveness of these compounds towards pathogenic bacteria, namely a complete photoinactivation with $6 \mu \mathrm{M} \mathrm{ZnPc4.1}$ for the tested model strains (E. faecalis and $P$. aeruginosa). There was observed a difference in the activity of the tetra-substituted ZnPc1.1-3.1 with the lack of any effect of non-peripheral ZnPc3.1. The Gram (-) bacterium P. aeruginosa was not inactivated even at high drug concentration such as $30 \mu \mathrm{M}$ ZnPcs. Two peripherally substituted ZnPc1.1 and ZnPc2.1 were evaluated with significant inactivations $(>3 \operatorname{logs})$. The studies on normal cell line suggested the lack of dark toxicity but after irradiation the phototoxicity occurred. The irradiation was carried out with light source LED 665$\mathrm{nm}$ on normal cells (Balb/c, 3T3) incubated with $\mathrm{ZnPc1}$ 1-4.1. The promising features of the zwitterionic $\mathrm{ZnPcs}$ are the lack of dark toxicity and a high phototoxicity at therapeutic light exposure on the normal cells.

In conclusion, the zwitterionic ZnPcs have charges influence on the uptakes and localization in an advanced way than the cationic $\mathrm{ZnPcs}$ derivatives $[39,58]$. Moreover, the resistant Gram (-) P. aeruginosa showed promising results with the octa-substituted $\mathrm{ZnPc} 4.1$ as a result of the optimal physicochemical properties of singlet oxygen generation. It was still low-effective to inactivate an early-stage biofilm even at high doses of $\mathrm{ZnPcs}$ with the response below 3logs. The problem with pathogens resistance and not so efficient treatment of biofilms with PDT approach features the needs for improvement of the applied procedure in order to have better PS distribution on the grown biofilms and the effective inactivation of the resistant pathogens. 


\section{$4 \mathrm{Lu}^{3+}$ and $\mathrm{Sn}^{4+}$ phthalocyanines towards pathogenic species}

The insertion of non-transition metal or semi-metal diamagnetic closed shell ions in the phthalocyanine core is well documented way for improvement of the main physicochemical properties associated with the excited states of the molecules [59]. The knowledge about the effect of the large atoms in regards to the photophysical properties of the phthalocyanine complexes (MPcs) is also well documented [60]. However, there are limited studies about the impact of the large metal ions $\left(\mathrm{Lu}^{3+}\right.$ and $\left.\mathrm{Sn}^{4+}\right)$ on the PDI efficiency. On one side, there is a steric hindrance effect due to the physical placement of large atoms out of the plane of macrocycle, which tends to lower the aggregation capacity of MPcs. On the other hand, the high coordination number of these metals permits attachment of one or more axial bulky groups of substituents, which also can decrease the aggregation behavior of the complexes.

Phthalocyanine complexes of lutetium ion $\left(\mathrm{Lu}^{3+}\right)$ have been of research interest due to their unique physicochemical properties and the ability for coordination of two or more Pc molecules [61, 62]. In regards to biomedical application, there is only one known Lu(III) complex, namely Lu(III)-texapyrine $\left(\right.$ Lu-tex $\left.{ }^{\mathrm{TM}}\right)$, which after many years of investigations, was considered for PDT and for diagnosis of cancer [63]. Nowadays the Lu(III)Pcs which are designed for PDT should be monomolecular and with cationic charge [64]. In our recent studies, two new water-soluble cationic lutetium (III) phthalocyanines (LuPcs) were synthesized and were investigated as effective towards fungus

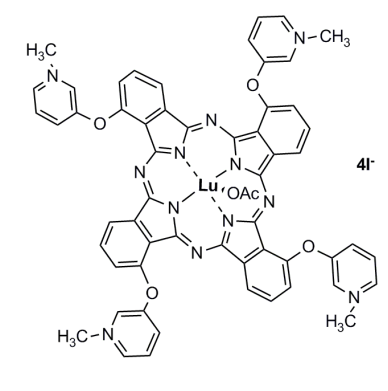

$(\mathrm{OAc})_{3} \mathrm{LuPc}, 1.1$

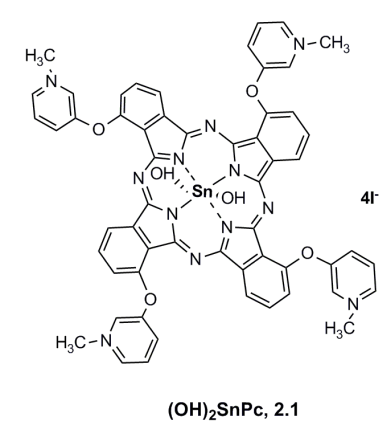

Candida albicans [65]. These are peripheral and nonperipheral Lu(III) phthalocyanines with four pyridyloxy groups which after methylation were converted to their water-soluble derivatives LuPc 1.1 and 1.2 (Fig. 6) [66].

The existing studies with tin (Sn(IV)) complexes for PDT are with purpurins, which were reported with an excellent PDT efficacy more than the related zinc complexes [70]. During 90s years this research resulted in a new PDT drug $\left(\mathrm{SnEt}_{2}\right)$ with very high potential to replace the originally clinically accepted porphyrin derivatives [67]. The known Sn(II/ IV) phthalocyanine complexes were explored with relatively high quantum yield of the triplet excited state and the favourable photophysicochemical properties $[68,69]$. In the similar way, two new $\mathrm{Sn}(\mathrm{IV})$ phthalocyanines (Sn4+Pcs) with hydroxyl groups on axial positions were synthesized. The obtained water-soluble Sn(IV)Pcs are the corresponding compounds to $\mathrm{Lu}(\mathrm{III}) \mathrm{Pcs}$, which are differing in the positions of methylpyridyloxy groups in non-peripheral (SnPc 2.1) and peripheral (SnPc 2.2) positions (Fig. 8).

\subsection{Synthesis of LuPcs and SnPcs}

The dinitriles, which are differed in the position of pyridyloxy- group namely 4-(3-pyridiloxy) nitrophthalonitrile (1) and 3-(3-pyridiloxy) phthalonitrile (2) were used as monomers for cyclotetramerization [70]. The synthetic procedure was previously applied for synthesis of other complexes of MPcs with N- quaternized atom. The $\mathrm{CN}$ group was confirmed with the sharp narrow band at $2228 \mathrm{~cm}^{-1}$ and the aromatic ether group with vibrations at 1280 and $1253 \mathrm{~cm}^{-1}$ in the IR spectrum.

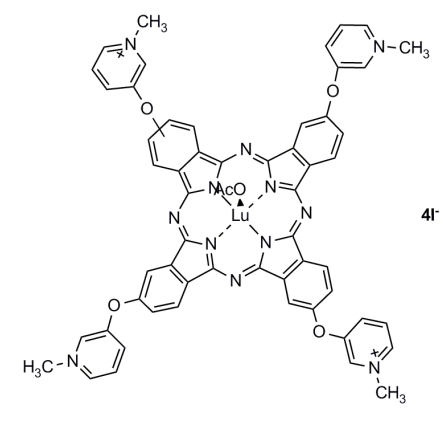

$(\mathrm{OAc})_{3} \mathrm{LuPc}, 1.2$

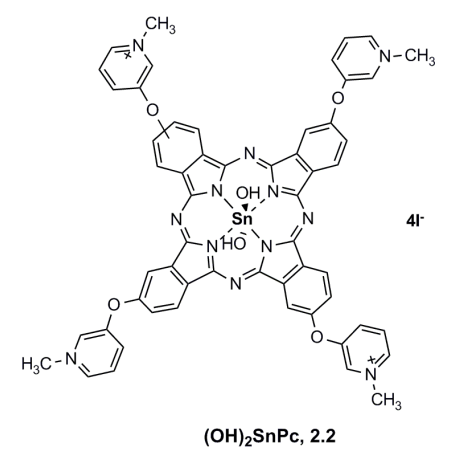

Fig. 8 Chemical structures of the studied MPcs coordinated with heavy metal ions of Lu(III) and Sn(IV). 
The molecular ion peak at $m / z 221[\mathrm{M}]^{+}$and two fragmentation ions peaks at $\mathrm{m} / z 127\left[\mathrm{M}-\mathrm{C}_{5} \mathrm{H}_{4} \mathrm{NO}^{-}\right]^{+}$and at $m / z \quad 78\left[\mathrm{C}_{5} \mathrm{H}_{4} \mathrm{~N}\right]^{+}$were obtained by means of MS spectroscopy. The cyclotetramerization reactions were carried out by addition of anhydrous salt of lutetium acetate and tin chloride by reflux in freshly distilled 1-pentanol, DBU in argon atmosphere. Another route involves Pc ring formation by the initial step of dissolved lithium pieces in n-pentanol. It was noticed the precipitation of the green product in 1-pentanol at the time of exchange of metal ions. The characteristic for the synthesis of $\mathrm{Lu}(\mathrm{III}) \mathrm{Pcs}$ is that the product was obtained as a mixture of three products, namely $\mathrm{Li}_{2} \mathrm{Pc}$, double-decker $\mathrm{LuPc}_{2}$ and the mono-molecular LuPc $(\sim 60 \%)$ plus other impurities. The purification by column flash chromatography resulted in positional (region) isomers of desired product. The chemical characterization performed by the routine analyses showed ${ }^{1} \mathrm{H}$ NMR spectra with shifting of the signals depending to the position of the substituents and for $\mathrm{CH}_{3}$ groups the recorded signals corresponded to the structures. IR spectra showed intense bands at $1237 \mathrm{~cm}^{-1}$ due to the presence of aromatic ether bonds (Ar-O-Ar). The mass spectra (MALDI-TOF) is characterized with a molecular peak $\mathrm{m} / \mathrm{z} 1214.718$ [MOAc+DHB] for 1 and $m / z 1214.398$ [M-OAc+DHB] for 2 . The final step of alkylation reaction was carried out with an excess of dimethyl sulphide or methyl iodide in DMF, which converted LuPcs into water-soluble derivatives 1.1 and 1.2. in relatively high yields (79-93\%) and purity [71].

The similar synthetic procedure was followed to prepare the water-soluble SnPcs (Fig. 6). The specificity in the synthesis of tin complexes is that two different complexes $\mathrm{Sn}(\mathrm{II}) \mathrm{Pcs}$ or $\mathrm{Sn}(\mathrm{IV}) \mathrm{Pcs}$ can be obtained in dependence on the molar ratio between the starting monomer (dinitriles) and the used salt $\left(\mathrm{SnCl}_{4}\right)$. The complex Sn(IV)Pc was prepared by using an equal ratio between both mixed solids. By addition of an excess of tin salt, Sn(II)Pc was synthesized. Taking into account our further experiments, we have prepared Sn(IV)Pcs, which are assumed to be more capable to limit the aggregation due to axial substituents of chlorine converted to hydroxyl group by pyridine in ammonium hydroxide treatment. The reactions were carried out in 1-pentanol for $5 \mathrm{~h}$ with lithium granules to facilitate the formation of Pc ring and then the tin metalation was performed with the same equivalent of $\mathrm{SnCl} 4$ as for the starting dinitrile at reflux for one additional hour. The purification of SnPcs 1 and 2 was carried out with dichloromethane (DCM) and methanol $(\mathrm{MeOH})$ in increasing of gradient of $\mathrm{MeOH}$. The watersoluble SnPcs 3 and 4 were washed in a series of solvents with different polarity and then dried on glass oven overnight. Four new Sn(IV)Pcs were chemically characterized with the routine analytical techniques. $1 \mathrm{H}$ NMR spectra corresponded to the predicted structures with a typical shifting of the signals depending to the position of the substituents. The signals of $\mathrm{CH}_{3}$ groups in the investigated compounds are well corresponding to the protons of four methyl groups. IR spectra showed the lack of the peak around $2230 \mathrm{~cm}^{-1}(\mathrm{C} \equiv \mathrm{N})$ and the appearance of new peak at $3304 \mathrm{~cm}^{-1}$ for the complex. The aliphatic hydrocarbons showed stretching at $2910-2985 \mathrm{~cm}^{-1}$ and for aromatic $\mathrm{C}-\mathrm{H}$ at 3015 to $3035 \mathrm{~cm}^{-1}$. The mass spectra were obtained with the signals of $\mathrm{M}+(1382)$ for SnPc2.1 and (1225) for SnPc2.2 which are $\mathrm{m} / \mathrm{z}$ of these compounds.

\subsection{Physicochemical properties}

Lutetium (Lu(III)) and Sn(IV) phthalocyanine complexes, which are differing only in the inserted metal ions were characterized with similar photo-physicochemical properties. Both complexes have red shifted absorption Q-band as compared to the same MPc with zinc metal ion ( $\mathrm{ZnPcMe})$. The absorption maxima were determined for the peripheral LuPc2 and SnPc2 at $675 \mathrm{~nm}$ and $678 \mathrm{~nm}$ in dimethylsulphoxide (DMSO) and even more shifted to $684 \mathrm{~nm}$ and $687 \mathrm{~nm}$ for non-peripheral LuPc4 and SnPc4 together with the low intensity peaks around $610 \mathrm{~nm}$ and the low-intensity B-bands between 360-367 nm. The quaternization of pyridyloxy-group leads to compounds with increased solubility but also to formation of the photo- inactive aggregates. For example, the absorption spectra of LuPcs (2 and 4) in water or buffer showed aggregation with a low intensity splitted Q-bands with appearance of the second band (681 nm for 2 and $692 \mathrm{~nm}$ for 4). Thus was previously observed with the other studies by us Mpcs (M: Zn, Al, In, Si, and Ge) with an exception of $\mathrm{Ga}(\mathrm{IV})$ Pcs, which exist as monomeric molecules in water [72]. The limitation of the formation of nonphotoactive aggregates is possible by addition of an anionic detergent or some hydrophobic vehicle molecules [73]. The undesirable tendencies of formation of photo- inactive associates in water are also minimal for experimental studies in buffered media of the fungal cell suspensions.

The fluorescence emission maxima were recorded at $704 \mathrm{~nm}$ and $721 \mathrm{~nm}$ for LuPcs and at $707 \mathrm{~nm}$ and $719 \mathrm{~nm}$ for SnPcs in DMSO (Fig. 9). The fluorescence spectra of Lu(III) Pcs and Sn(IV) Pcs showed a long red shift of the emission maximum (29-36 nm) as compared to the absorption maxima of Q-bands. The proximity of the wavelength in absorption and excitation spectra is indicative for the nuclear configurations of the ground and excited states, which are not affected by the excitation wavelength ( $365 \mathrm{~nm}, 635 \mathrm{~nm}$, and $660 \mathrm{~nm})$.

The fluorescence lifetime ( $\left.\tau_{F}\right)$ of a compound suggests the time interval, in which it can participates in photosensitization process. The fluorescence decay curves were mono-exponential and typical for non-aggregated molecular species. The fluorescence properties of quantum yield and lifetime of the complexes with the both metals $\left(\mathrm{Lu}^{3+}\right.$ and $\left.\mathrm{Sn}^{4+}\right)$ and the same substituted zinc complex ( $\mathrm{ZnPcMe})$ showed that the heavy atom ions complexes have relatively low quantum yields $(0.01-0.08)$ and also lifetimes (2.24 ns for LuPc1.2 and 3.27 ns for LuPc1.1) as compared to the same properties of $\mathrm{ZnPcMe}$, which have higher values (respectively $0.2 ; 3.99 \mathrm{~ns}$ ). The very fast quenching of the fluorescence can be explained also by the presence of bulky substituents as well as the differences in the location of substitution groups so that the nonperipheral complexes underwent a faster quenching of the 
fluorescence signal showing the shorter life-time than the peripheral derivatives.

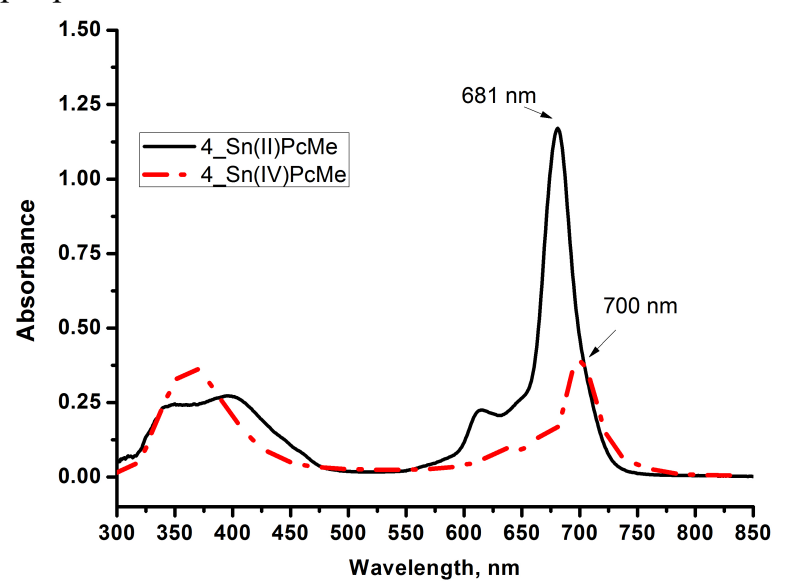

(a)

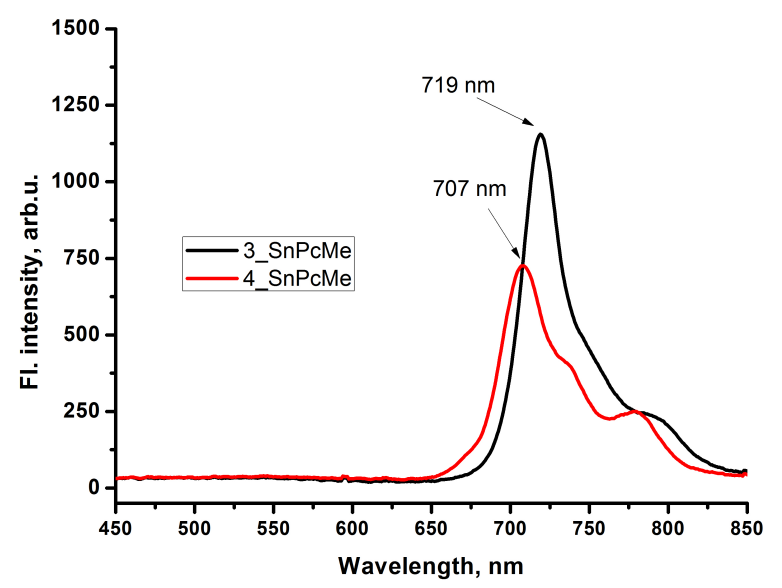

(b)

Fig. 9 (a) Absorption spectra of $\mathrm{Sn}(\mathrm{II})$ vs $\mathrm{Sn}(\mathrm{IV})$ phthalocyanines, 2.2 and (b) fluorescence spectra of both new $\mathrm{Sn}(\mathrm{IV})$ phthalocyanines (2.1 and 2.2).

The capability of the both complexes of Lu(III) and $\mathrm{Sn}(\mathrm{IV})$ to produce singlet oxygen was measured in DMSO solutions in order to avoid some aggregation. The used indirect photochemical method is based on the oxidation of a chemical substrate 1,3-Diphenylisobenzofuran (DPBF) from the generated in the reaction vesicle molecular singlet oxygen during specific light irradiation. The calculations were performed referred to the quantum yield of the standard compound ( $\mathrm{ZnPc}, 0.67$ in DMSO) [74]). The values of singlet oxygen quantum yield were similar, namely 0.32 and 0.35 for LuPcs (1.1 and 1.2). In conclusion there is no significant difference in the singlet oxygen quantum yields by the replacement of $\mathrm{Zn}$ (II) and Al(III) with the large atom ions of $\mathrm{Lu}(\mathrm{III})$ and $\mathrm{Sn}(\mathrm{IV})$. The studies showed that there was significant decrease in the fluorescence quantum yields of Lu(III)- and Sn(IV) Pcs but not so much in their singlet oxygen quantum yields of importance for PDI efficacy.

\subsection{Uptake and localization of Lu(III) phthalocyanines}

The promising physicochemical properties of the watersoluble cationic Lu(III)- and Sn(IV)- phthalocyanines are the base for their photobiological investigations on pathogenic species. The expansion of the sensitiser uptake is known to depend on the structural modifications, one of which is the lack of symmetry in large atom's coordinated MPc molecules. Candida albicans is the most prevalent pathogen representing about $60 \%$ of all yeasts isolated in clinical samples. The uptake and localization studies were performed on the suspensions of following the fluorescence. The molecules attached to $C$. albicans cells were calculated on the basis of the fluorescence intensity of the spectra taken from extracted samples and referring to the calibration curves recorded for the same compound in the extraction mixture $[74,75]$. The uptakes of LuPcs $(3 \mu \mathrm{M})$ for different cellular suspensions $\left(10^{5}-10^{8} \mathrm{CFU} \mathrm{mL} \mathrm{m}^{-1}\right)$ followed the typical decrease of uptake with increase of the cell density. The samples were taken from the supernatant (1) in Phosphate-buffered saline (PBS) after incubation, (2) in PBS after $1^{\text {st }}$ and $2^{\text {nd }}$ cell wash, and (3) after cell extraction with a mixture of 2\% Sodium dodecyl sulphate (SDS): Tetrahydrofuran (THF) or Dimethylformamide (DMF) $(9: 1)$ depends on the solubility of the studied compound. The obtained line dependence suggests that both Lu(III)Pcs and Sn(IV)Pcs are reliable to uptake into fungal cells and in amounts, which are not in a dependence on the coordinated metal ions. The typical inverse dependence of the decrease of the number of molecules accumulated into fungal cells with increase of the cell density was observed with a steep slope for the both LuPcs.

It is well accepted that cationic dyes are more likely to taken up by the bacterial and fungal species as a result of the nature of the cell wall and the binding process tend to occur via an electrostatic mechanism of interactions $[76,77]$. The fluorescence confocal microscopy studies showed that the water-soluble cationic LuPcs have the surface localization in fungal cells with relatively high amount and in biofilms with extension inside the fungal cells. The full penetration into 48-h developed fungal biofilm occurred preferably on the cell wall and in the cytoplasm. The green fluorescence taken at excitation $488 \mathrm{~nm}$ and emission $500-580 \mathrm{~nm}$ shows the native fluorescence of the biofilm. The typical red fluorescence was observed for excitation with laser $635 \mathrm{~nm}$ and emission 660-740 nm. The formed C. albicans biofilms were determined with thicknesses between 17 and $23 \mu \mathrm{m}$ and the scans on the slices showed the fluorescence within the whole biomass suggesting the full penetration of LuPcs.

The confocal fluorescence study of biofilms with Sn(IV) Pcs was not possible perhaps of the poor fluorescence intensity of the tin containing photosensitizers. The reason may be due to an improper excitation spectrum, which has limited light penetration and in case of fungal cells the cells inactivation may have happened layer by layer till the whole biofilm destruction 
in a single step of irradiation. The phthalocyanine complexes with the same substituents but with different metal ions (ZnPcMe, SiPc1, GePc1, GaPc1 and GaPc2) were with approximately $2 / 3$ limited penetration on the basis of the entire biofilm $[66,74]$. The observation that $\mathrm{Lu}$ (III)Pcs completely penetrate into 48-h fungal biofilm can be explained with the cationic charge of the methylpyridyloxy groups as well as with some loss of planarity of the Pc ring due to large size of Lu atom. Even so the fungal biofilms incubated with LuPcs demonstrated the full penetration depth after the proper light excitation $(635 \mathrm{~nm})$ but very low photodynamic response $(<3 \log )$ on the studied biofilms. [74]. The uptake and localization behaviour of Lu(III)Pcs seems to be in advance to their application in optical diagnosis. The complexes with large atom ions such as lutetium and tin together with the charge feature are an effective structure approach for improvement of the photosensitizer's penetration and selectivity for better photodynamic inactivation.

\subsection{In vitro study on C. albicans}

The phthalocyanine complexes with large atoms of Lu(III) and $\mathrm{Sn}(\mathrm{IV})$ were studied for their antimicrobial photodynamic efficacy on the pathogenic fungus C. albicans as suspension with density of approximately $10^{7} \mathrm{CFU} \cdot \mathrm{mL}^{-1}[78]$. The studies were carried out with a wide concentration range of $\mathrm{Lu}(\mathrm{III})$ - and $\mathrm{Sn}(\mathrm{IV})$-Pcs $(1 \mu \mathrm{M}-30 \mu \mathrm{M})$. The photodynamic response towards C. albicans was lower than $3 \log$ for $1-20 \mu \mathrm{M}$ MPcs. The photoinactivation studies suggested that despite the significant uptake of both kinds of MPcs tested in these concentrations, the complete photo-inactivation was observed over $20 \mu \mathrm{M}$ at the optimal tested light parameters $\left(50 \mathrm{~J} \cdot \mathrm{cm}^{-2}\right.$ and $\left.60 \mathrm{~mW} \cdot \mathrm{cm}^{-2}\right)$. Lu(III)Pcs as well as Sn(IV)Pcs showed lack of dark toxicity for the studied concentrations. Considering the impact of the coordinated metal ion, the PDT effect of water-soluble LuPcs was studied in comparison to $\mathrm{Zn}$ (II) phthalocyanine with the same functional groups as substituents ( $\mathrm{ZnPcMe})$. At as low concentration as $3 \mu \mathrm{M}$ MPcs the lower uptake was determined for the both LuPcs as compared to the uptake of $\mathrm{ZnPcMe}$ for $C$. albicans within a range of cell density $\left(10^{5}-10^{8} \mathrm{CFU} / \mathrm{mL}\right) . \mathrm{Zn}(\mathrm{II})$ and $\mathrm{Si}(\mathrm{IV})$ coordinated complexes were studied with higher phototoxic effects towards C.albicans for lower concentrations than that needed with LuPcs and SnPcs. All PDT studies were performed without cell washing after incubation followed by exposure with mild light dose $\left(50 \mathrm{~J} \cdot \mathrm{cm}^{-2}\right)$ from a specific light source (LEDs emitted at 635 or $665 \mathrm{~nm}$ ). The relatively high singlet oxygen quantum yields and high uptake in cells resulted in low PDI effect which can be explained with the lower cell susceptibility to singlet oxygen and another ROS.

The comparisons of the PDT responses of Lu(III)Pcs versus $\mathrm{Sn}(\mathrm{IV}) \mathrm{Pcs}$ on $C$. albicans planktonic and biofilm showed that $\mathrm{ZnPcMe}$, which has the same substituents and differs only with $\mathrm{Zn}$ (II) coordination showed the photoinactivation with higher activity towards pathogens in suspension as well as biofilms. The molecular electronic structure due to replacement of $\mathrm{Zn}$ (II) with $\mathrm{Lu}(\mathrm{III})$ or $\mathrm{Sn}(\mathrm{IV})$ has changed the photophysical parameters but doesn't influence in a positive way on the photodynamic efficiency. The much harsh photodynamic conditions are needed together with repetitive application of the procedure in order to be effective the treatment of pathogens biofilms.

\section{Conclusions}

The knowledge of the structural characteristics, composition, location and nature of the substituents, the charge of the molecules and the effect these features have on the pharmacokinetic characteristics of phthalocyanine complexes used as photosensitive compounds for PDT of tumour cells and PDI of pathogenic microorganisms are essential.

The biologically active substituents used to increase selectivity of phthalocyanine complexes with respect to the treated objects give specific characteristics to these compounds both in terms of accumulation and in terms of localization in cellular structures and in the ways of treating the objects in order to increase the efficiency of light-activated photodynamic reactions.

The coordination of the phthalocyanine complex by means of large metal ions provides additional opportunities both for optimizing the physicochemical and pharmacokinetic characteristics of these complexes and for realizing compounds with different hydrophobicity. It is also a promising method for increasing their efficiency and reducing the toxicity of phthalocyanine complexes in their functionalization with bioactive conjugates such as sugars, sterols and amino acids.

In the use of phthalocyanine complexes for PDI of pathogenic microorganisms, the realization of compounds with affinity to the potential of bacteria membrane is of extremely importance for efficiency.

In conclusion, in terms of the realization of even more effective phthalocyanine photosensitizers, in-depth additional and appropriate studies are necessary to link the effectiveness of PDT with the structure of the compounds.

\section{Disclosures}

All authors declare that there is no conflict of interests in this paper.

\section{Acknowledgments}

The authors of this review thanks the Bulgarian National Science Fund for support with the project KP-06-H29/11/2018, KP-06-H23/8/2018 and KP-06-H38/13/2019. 


\section{References}

1. N. Moldonado-Carmona, T.-S. Ouk, M. J. F. Calvete, M. M. Pereira, N. Villandier, and S. Leroy-Lhez, "Conjugating biomaterials with photosensitizers: advances and perspectives for photodynamic antimicrobial chemotherapy," Photochemical \& Photobiological Sciences 19(4), 445-461 (2020).

2. P.-C. Lo, M. S. Rodriges-Morgade, R. K. Pandey, D. K. P. Ng, T. Torres, and F. Dumoulin, "The unique features and promises of phthalocyanines as advanced photosensitisers for photodynamic therapy of cancer," Chemical Society Reviews 49(4), 1041-1056 (2020).

3. X. Li, B.-D. Zheng, X.-H. Peng, S.-Z. Li, J.-W. Ying, Y. Zhao, J.-D. Huang, and J. Yoon, "Phthalocyanines as medicinal photosensitizers: Developments in the last five years," Coordination Chemistry Review 379, 147-160 (2019).

4. N. Sekkat, H. van der Bergh, T. Nyokong, and N. Lange, "Like a Bolt from the Blue: Phthalocyanines in Biomedical Optics," Molecules 17(1), 98-144 (2012).

5. A. Segalla, C. D. Borsarelli, S. E. Braslavsky, J. D. Spikes, G. Roncucci, D. Dei, G. Chiti, G. Jori, and E. Reddi, "Photophysical, photochemical and antibacterial photosensitizing properties of a novel octacationic Zn(ii)phthalocyanine," Photochemical \& Photobiological Sciences 1(9), 641-648 (2002).

6. T. C. White, K. A. Marr, and R. A. Bowden, "Clinical, cellular, and molecular factors that contribute to antifungal drug resistance,” Clinical Microbiology Reviews 11(2), 382-402 (1998).

7. J. M. Dabrowski, B. Pucelik, A. Regiel-Futyra, M. Brindell, O. Mazuryk, A. Kyzioł, G. Stochel, W. Macyk, and L. G. Arnaut, "Engineering of relevant photodynamic processes through structural modifications of metallotetrapyrrolic photosensitizers," Coordination Chemistry Reviews 325, 67-101 (2016).

8. L. Sobotta, P. Skupin-Mrugalska, J. Piskorz, and J. Mielcarek, "Porphyrinoid photosensitizers mediated photodynamic inactivation against bacteria," European Journal of Medicinal Chemistry 175, 72-106 (2019).

9. V. Almeida-Marrero, J. A. Gonzales-Delgado, and T. Torres, "Emerging Perspectives on Applications of Porphyrinoids for Photodynamic Therapy and Photoinactivation of Microorganisms," Macroheterocycles 12(1), 816 (2019).

10. V. Mantareva, I. Angelov, D. Wöhrle, E. Borisova, and V. Kussovski, "Metallophthalocyanines for antimicrobial photodynamic therapy: an overview of our experience," Journal of Porphyrins and Phthalocyanines 17(6-7), 399416 (2013).

11. F. M. Lauro, P. Pretto, L. Covolo, G. Jori, and G. Bertoloni, "Photoinactivation of bacterial strains involved in periodontal diseases sensitized by porphycene-polylysine conjugates," Photochemical \& Photobiological Sciences 1(7), 468-470 (2002).

12. T. N. Demidova, M. R. Hamblin, "Effect of cell-photosensitizer binding and cell density on microbial photoinactivation," Antimicrobial Agents and Chemotherapy 49(6), 2329-2335 (2005).

13. C. A. Pereira, R. L. Romeiro, A. C. B. P. Costa, A. K. S. MacHado, J. C. Junqueira, and A. O. C. Jorge, "Susceptibility of Candida albicans, Staphylococcus aureus, and Streptococcus mutans biofilms to photodynamic inactivation: an in vitro study," Lasers in Medical Science 26(3), 341-348 (2011).

14. M. A. DiPalma, M. G. Alvarez, A. L. Ochoa, M. E. Milanesio, and E. N. Durantini, “Optimization of cellular uptake of zinc(II) 2,9,16,23-tetrakis[4-(N-methylpyridyloxy)] phthalocyanine for maximal photoinactivation of Candida albicans," Fungal Biology 117(11-12), 744-751 (2013).

15. B. S. Vig, K. M. Huttunen, K. Laine, and J. Rautio, "Amino acids as promoieties in prodrug design and development," Advanced Drug Delivery Reviews 65(10), 1370-1385 (2013).

16. L. S. Li, Z. P. Luo, Z. Chen, J. C. Chen, S. Y. Zhou, P. Xu, P. Hu, J. D. Wang, N. S. Chen, J. L. Huang, and M. D. Huang, "Enhanced Photodynamic Efficacy of Zinc Phthalocyanine by Conjugating to Heptalysine," Bioconjugate Chemistry 23(11), 2168-2172 (2012).

17. T. Dougherty, "An update on photodynamic therapy applications," Journal of Clinical Laser Medicine \& Surgery 20(1), 3-7 (2002).

18. R. Malik, A. Manocha, and D. K. Suresh, "Photodynamic therapy - A strategic review," Indian Journal of Dental Research 21(2), 285-291 (2010).

19. V. Mantareva, V. Kussovski, and I. Angelov, "Cationic Metal Phthalocyanines as Effective Photosensitizers Towards Pathogenic Microorganisms," Chapter 5 in Photosensitizers: Types, Uses and selected Research, C. Withmire (Ed.), Nova Science Publishers, New York (2016).

20. M. Garcia-Iglesias, E. Huerta, "Towards new multivalent supramolecular helical structures based on phthalocyanines for PDT applications," Journal of Porphyrins and Phthalocyanines 21(11), 745-750 (2017).

21. M. Wainwright, Photosensitizers in Biomedicine, John Wiley and Sons, Chichester, UK (2009). ISBN: 978-0-47074494-9.

22. M.-R. Ke, J. M. Eastel, K. L. K. Ngai, Y.-Y. Cheung, P. K. S. Chan, M. Hui, D. K. P. Ng, and P.-C. Lo, "Photodynamic inactivation of bacteria and viruses using two monosubstituted zinc(II) phthalocyanines," European Journal of Medicinal Chemistry 84, 278-283 (2014). 
23. J. D. Miller, E. D. Baron, H. Scull, A. Hsia, J. C. Berlin, T. Mc Cormick, V. Colussi, M. E. Kenney, K. D. Cooper, and N. L. Oleinick, "Photodynamic therapy with the phthalocyanine photosensitizer Pc 4: the case experience with preclinical mechanistic and early clinical-translational studies,” Toxicology and Applied Pharmacology 224(3), 290299 (2007).

24. F. Dumoulin, M. Durmus, V. Ahsen, and T. Nyokong, "Synthetic pathways to water-soluble phthalocyanines and close analogs," Coordination Chemistry Reviews 254(23-24), 2792-2847 (2010).

25. N. Kuznetsova, N. Gretsova, E. Kalmykova, E. Makarova, S. Dashkevich, V. Negrimovskii, O. Kaliya, and E. Lukyanets, "Relationship between the photochemical properties and structure of pophyrins and related compounds," Russian Journal of General Chemistry 70(1), 133-140 (2000) [in Russian].

26. A. V. Ziminov, Y. A. Sidunets, V. S. Fundamensky, V. V. Gurzhiy, and S. M. Rams, "Synthesis, characterization, and investigation of photochemical properties of tetra-substituted zinc phthalocyanines bearing 4-(3,5-dimethyl-1Hpyrazol-1-yl)phenyl moiety with different linker heteroatoms," Inorganica Chimica Acta 501, 119306 (2020).

27. E. Guzel, A. Gunsel, B. Tuzun, G. Y. Atmaca, A. T. Bilgicli, A. Erdogmus, and M. N. Yarasir, "Synthesis of tetrasubstituted metallophthalocyanines: Spectral, structural, computational studies and investigation of their photophysical and photochemical properties," Polyhedron 158, 316-324 (2019).

28. S. A. Mikhalenko, L. I. Soloveela, and E. A. Lukyanetz, "Phthalocyanines and Related Compounds: XXXVII. Synthesis of Covalent Conjugates of Carboxy-substituted Phthalocyanines with $\alpha$-Amino Acids," Russian Journal of General Chemistry 74(3), 451-459 (2004).

29. E. A. Lukyanetz, V. N. Nemykin, "The key role of peripheral substituents in the chemistry of phthalocyanines and their analogs," Journal of Porphyrins and Phthalocyanines 14(01), 1-40 (2010).

30. Ao Wang, R. Zhou, L. Zhou, K. Sun, J. Jiang, and S. Wei, Positively charged phthalocyanine-arginine conjugates as efficient photosensitizer for photodynamic therapy, Bioorganic \& Medicinal Chemistry 25(1), 1643-1651 (2017).

31. N. Nombona, E. Antunes, W. Chidawanyika, P. Kleyi, Z. Tshentu, and T. Nyokong, "Synthesis, photophysics and photochemistry of phthalocyanine- $\varepsilon$-polylysine conjugates in the presence of metal nanoparticles against Staphylococcus aureus," Journal of Photochemistry and Photobiology A: Chemistry 233, 24-33 (2012).

32. Q. Sun, B.-Y. Zheng, Y.-H. Zhang, J.-J. Zhuang, M.-R. Ke, and J. D. Huang, "Highly photocytotoxic silicon(IV) phthalocyanines axially modified with 1-tyrosine derivatives: Effects of mode of axial substituent connection and of formulation on photodynamic activity," Dyes and Pigments 141, 521-529 (2017).

33. M. R. Ke, J. M. Eastel, K. L. K. Ngai, Y. Y. Cheung, P. K. S. Chan, M. Hui, D. K. P. Ng and P. C. Lo, "Oligolysineconjugated zinc(II) phthalocyanines as efficient photosensitizers for antimicrobial photodynamic therapy," Chemistry-An Asian Journal 9(7), 1868-1875 (2014).

34. D. Wöhrle, M. Eskes, K. Shigehara, and A. Yamada, “A Simple Synthesis of 4, 5-Disubstituted 1, 2-Dicyanobenzenes and 2, 3, 9, 10, 16, 17, 23, 24-Octasubstituted Phthalocyanines," Synthesis 1993(02), 194-196 (1993).

35. S. E. Maree, T. Nyokong, "Syntheses and photochemical properties of octasubstituted phthalocyaninato zinc complexes," Journal of Porphyrins and Phthalocyanines 5(11), 782-792 (2001).

36. M. B. Aliosman, I. Z. Eneva, I. B. Stoineva, M. Durmus, and V. N. Mantareva, "Aminophenoxy-substituted zinc (II) phthalocyanines as basic photosensitizers for conjugation with biologically active moieties via amide bond," Bulgarian Chemical Communications 49, (2017), 79-85.

37. X.-F. Zhang, X. Li, L. Niu, L. Sun, and L. Liu, "Charge Transfer Photophysics of Tetra $(\alpha$-amino) Zinc Phthalocyanine," Journal of Fluorescence 19(6), 947-954 (2009).

38. L. Sobotta, S. Lijewski, J. Dlugaszewska, J. Nowicka, J. Mielcarek, and T. Goslinski, "Photodynamic inactivation of Enterococcus faecalis by conjugates of zinc (II) phthalocyanines with thymol and carvacrol loaded into lipid vesicles," Inorganica Chimica Acta 489, 180-190 (2019).

39. D. Lin, Y. Wang, Q. Zhan, J. Zhou, L. Zhou, and S. Wei, "The substituted amino group type dependent sensitivity enhancing of cationic phthalocyanine derivatives for photodynamic activity," Journal of Photochemistry and Photobiology A: Chemistry 315, 107-120 (2016).

40. A. Shrestha, A. Kishen, "Polycationic Chitosan-Conjugated Photosensitizer for Antibacterial Photodynamic Therapy," Photochemistry and Photobiology 88(3), 577-583 (2012).

41. V. Mantareva, I. Angelov, V. Kussovski, R. Dimitrov, L. Lapok, and D. Wörhle, "Photodynamic efficacy of watersoluble $\mathrm{Si}(\mathrm{IV})$ and Ge(IV) phthalocyanines towards Candida albicans planktonic and biofilm cultures," European Journal of Medicinal Chemistry 46(9), 4430-4440 (2011).

42. I. Angelov, A. Kril, R. Dimitrov, E. Borisova, L. Avramov, and V. Mantareva, "Light enhancement of in vitro antitumor activity of galactosylated phthalocyanines," Photonics \& Lasers in Medicine 5(2), 123-140 (2016).

43. V. Mantareva, M. Syuleyman, A. Slavova-Kazakova, I. Angelov, and M. Durmus, "Mestranol moieties clicked to $\mathrm{Zn}(\mathrm{II})$ phthalocyanine for controllable photosensitized oxidation of cholesterol," Archives of Biotechnology and Biomedicine, 041-048 (2021).

44. M. Aliosman, I. Angelov, Y. Mitrev, I. Iliev, M. Durmuş, and V. Mamtareva, "Novel Zn(II) phthalocyanine with tyrosine moieties for photodynamic therapy: Synthesis and comparative study of light-associated properties," Polyhedron 162, 121-128 (2019). 
45. V. Mantareva, M. Aliosman, M. Durmuş, and I. Angelov, "Amino acids substituted phthalocyanine complexes: an overview on the synthetic approaches and UV-vis properties related to photodynamic applications," Bulgarian Chemical Communications 50, 185-192 (2018).

46. S. Hermann, A. H. Wagenknecht, "Synthesis of N,N-dimethylaminopyrene-modified short peptides for chemical photocatalysis," Journal of Peptide Science 23(7-8), 563-566 (2017).

47. B. Kiyak, A. A. Esenpinar, and M. Balut, "Synthesis, characterization, photophysical and photochemical properties of zinc and indium phthalocyanines bearing a vanillylacetone moiety known as an anticarcinogenic agent," Polyhedron 90, 183-196 (2015).

48. A. Ogunsipe, D. Maree, and T. Nyokong, "Solvent effects on the photochemical and fluorescence properties of zinc phthalocyanine derivatives," Journal of Molecular Structure 650(1-3), 131-140 (2003).

49. S. K. Sharma, T. Dai, G. B. Kharkwal, Y.-Y. Huang, L. Huang, V. J. B. de Arce, G. P. Tegos, and M. R. Hamblin, "Drug discovery of antimicrobial photosensitizers using animal models," Current Pharmaceutical Design 17(13), 1303-1319 (2011).

50. W. C. M. A. Melo, L. F. Castro, and R. M. M. T. S. Dal'Mas, "Effectiveness of photodynamic therapy on gramnegative bacteria," in Science Against Microbial Pathogens: Communicating Current Researchand Technological Advances 3, Badajos, Spain, 662-667 (2011).

51. V. Kussovski, V. Mantareva, I. Angelov, P. Orozova, D. Wohrle, G. Schnurpfeil, E. Borisova, and L. Avramov, "Photodynamic inactivation of Aeromonas hydrophila by cationic phthalocyanines with different hydrophobicity," FEMS Microbiology Letters 294(2), 133-140 (2009).

52. V. Mantareva, I. Angelov, V. Kussovski, D. Woehrle, and S. Dimitrov, "Metallophthalocyanines as photodynamic sensitizers for treatment of pathogenic bacteria. Uptake and photoinactivation properties," Comptes Rendus de l'Acade'mie Bulgare des Sciences 63(1), 77-84 (2010).

53. V. Mantareva, I. Angelov, D. Wohrle, V. Dogandhiyska, S. Dimitrov, and V. Kussovski, "Water-soluble phthalocyanine complexes of Ga(III) and In(III) in the photodynamic inactivation of pathogenic fungus," Proceedings of SPIE 7747, 774712 (2011).

54. V. Mantareva, I. Angelov, V. Kussovski, and S. Dimitrov, "Advanced photodynamic inactivation of dental pathogenic microorganisms with water-soluble and cationic phthalocyanines," in Science Against Microbial Pathogens: Communicating Current Research and Technological Advances 1(11), FORMATEX Research Centre, Badajos, Spain, 650-661 (2011).

55. I. Angelov, V. Mantareva, V. Kussovski, D. Woehrle, H. Kisov, M. Belcheva, T. Georgieva, and S. Dimitrov, "Susceptibility of representative Dental Pathogens to inactivation by the PDT with water-soluble photosensitizers," Proceedings of SPIE 7994, 79941A (2011).

56. R. Gergova, T. Georgieva, I. Angelov, V. Mantareva, S. Valkanov, I. Mitov, and S. Dimitrov, "Photodynamic therapy with water-soluble phtalocyanines against bacterial biofilms in teeth root canals," Proceedings of SPIE 8427, 842744 (2012).

57. V. Kussovski, V. Mantareva, I. Angelov, L. Avramov, E. Popova, and S. Dimitrov, “Al(III), Pd(II) and Zn(II) phthalocyanines for inactivation of dental pathogen Aggregatibacter actinomycetemcomitans as planktonic and biofilm-cultures," Proceedings of SPIE 8427, 84273X (2012).

58. C. Gol, M. Durmus, "Investigation of photophysical, photochemical and bovine serum albumin binding properties of novel water-soluble zwitterionic zinc phthalocyanine complexes," Synthetic Metals 162(7-8), 605-613 (2012).

59. G. Dilber, M. Durmus, and H. Kantekin, "Non-aggregated zwitterionic Zinc (II) phthalocyanine complexes in water with high singlet oxygen quantum yield," Dyes and Pigments 160, 267-284 (2019).

60. S. Colak, M. Durmus, and S. Z. Yildiz, "Investigation of the photophysical and photochemical properties of peripherally tetra-substituted water-soluble zwitterionic and cationic zinc (II) phthalocyanines," Dalton Transactions 45(25), 10402-10410 (2016).

61. V. N. Nemykin, E. A. Luk'yanets, "11 The Key Role of Peripheral Substituents in Chemistry of Phthalocyanines," in Handbook of Porphyrin Science vol. 3, K. Kadish, K. M. Smith, and R. Guilard (Eds.), Word Scientific Publishing, Singapore, 1-323 (2010).

62. F. Foschi, C. R. Fontana, K. Ruggiero, R. Riahi, A. Vera, A. G. Doukas, T.C. Pagonis, R. Kent, P. P. Stashenko, and N. S. Soukos, "Photodynamic inactivation of Enterococcus faecalis in dental root canals in vitro," Lasers in Surgery and Medicine: The Official Journal of the American Society for Laser Medicine and Surgery 39(10), 782-787 (2007).

63. E. P. Prochnow, M. R. Martins, C. B. Campagnolo, R. C. Vianna, M. A. Villetti, and K. Z. Kantorski, “Antimicrobial photodynamic effect of phenothiazinic photosensitizers in formulations with ethanol on Pseudomonas aeruginosa biofilms," Photodiagnosis and Photodynamic Therapy 13, 291-296 (2016).

64. V. Mantareva, C. Gol, V. Kussovski, M. Durmus, and I. Angelov, "Impact of water-soluble zwitterionic Zn(II) phthalocyanines against pathogenic bacteria," Zeitschrift für Naturforschung C 74(7-8), 183-191 (2019).

65. V. Mantareva, V. Kussovski, I. Angelov, D. Wöhrle, R. Dimitrov, E. Popova, and S. Dimitrov, "Non-aggregated Ga (III)-phthalocyanines in the photodynamic inactivatio planktonic and biofilm cultures of pathogenic microorganisms," Photochemical \& Photobiological Sciences 10(1), 92-102 (2011). 
66. V. Mantareva, V. Kussovski, I. Angelov, E. Borisova, L. Avramov, G. Schnurpfeil, and D. Wöhrle, "Photodynamic activity of water-soluble phthalocyanine zinc (II) complexes against pathogenic microorganisms," Bioorganic \& Medicinal Chemistry 15(14), 4829-4835 (2007).

67. M. Wainwrigh, T. Maisch, S. Nonell, K. Plaetzer, A. Almeida, G. P. Tegos, and M. R. Hamblin, "Photoantimicrobials-are we afraid of the light?" The Lancet Infectious Diseases 17(2), e49-e55 (2017).

68. V. Kussovski, V. Mantareva, M. Durmus, and I. Angelov, "Quaternized Zn (II) phthalocyanines for photodynamic strategy against resistant periodontal bacteria," Zeitschrift für Naturforschung C 73(5-6), 221-228 (2018).

69. T. Nyokong, "Effects of substituents on the photochemical and photophysical properties of main group metal phthalocyanines," Coordination Chemistry Reviews 251(13-14), 1707-1722 (2007).

70. M. Durmus, S. Yeslot, B. Cosut, A. Gul Gurek, A. Kilic, and V. Ahsen, "Comparison of photophysicochemical properties of hexaphenoxycyclotriphosphazenyl-substituted metal-free, mono-and bis-lutetium phthalocyanines," Synthetic metals 160(5-6), 436-444 (2010).

71. R. Zugle, C. Litwinski, and T. Nyokong, "Photophysical characterization of dysprosium, erbium and lutetium phthalocyanines tetrasubstituted with phenoxy groups at non-peripheral positions," Polyhedron 30(9), 1612-1619 (2011).

72. F. L. Lu, "The effects of substituents, molecular symmetry, ionic radius of the rare earth metal, and macrocycle on the electronic absorption spectra characteristics of sandwich-type bis(phthalocyaninato) and mixed (phthalocyaninato)(porphyrinato) rare earth complexes," Polyhedron 26(14), 3939-3946 (2007).

73. J. L. Sessler, G. Hemmi, T. D. Mody, T. Murai, A. K. Burrell, and S. W. Young, "Texaphyrins: synthesis and applications," Accounts of Chemical Research 27(2), 43-50 (1994).

74. V. Mantareva, M. Durmus, M. Aliosman, I. Stoineva, and I. Angelov, "Lutetium(III) acetate phthalocyanines for photodynamic therapy applications: Synthesis and photophysicochemical properties," Photodiagnosis and Photodynamic Therapy 14, 98-103 (2016).

75. V. Mantareva, V. Kussovski, M. Durmus, E. Borisova, and I. Angelov, "Photodynamic inactivation of pathogenic species Pseudomonas aeruginosa and Candida albicans with lutetium (III) acetate phthalocyanines and specific light irradiation," Lasers in Medical Science 31(8), 1591-1598 (2016).

76. N. Masilela, T. Nyokong, "The synthesis and photophysical properties of novel cationic tetra pyridyloxy substituted aluminium, silicon and titanium phthalocyanines in water," Journal of Luminescence 130(10), 1787-1793 (2010).

77. D. Wöhrle, N. Iskander, G. Graschew, H. Sinn, E. Friedrich, W. Maier-Borst, J. Stern, and P. Schlag, "Synthesis of positively charged phthalocyanines and their activity in the photodynamic therapy of cancer cells," Photochemistry and Photobiology 51(3), 351-356 (1990).

78. I. Eneva, M. Aliosman, I. Angelov, K. Popov, and V. Mantareva, "Mono-ring phthalocyanine complexes of large ions Lu3+ and Sn4+: synthesis and comparison of photophysical properties," Bulgarian Chemical Communications 49(D), 246-252 (2017). 